\title{
Algunos aspectos etológicos de la comunicación química en ratas $y$ ratones de laboratorio.
}

Revisión

Ana G. Gutiérrez-García, Carlos M. Contreras.

Laboratorio de Neurofarmacología, Instituto de Neuroetología, Universidad Veracruzana e Instituto de Investigaciones Biomédicas, Universidad Nacional Autónoma de México. Xalapa, Veracruz, México.

\section{RESUMEN.}

La comunicación química a través de las feromonas, es fundamental para las relaciones intraespecíficas. Estas sustancias son particularmente importantes para promover la reproducción, el apareamiento, la inhibición o el desencadenamiento del comportamiento agresivo, la identificación entre grupos y entre individuos, la organización social, el marcaje territorial y el miedo, entre otras pautas conductuales. Diversos estudios han determinado que la presencia de sustancias de naturaleza volátil en la orina de ratas, satisfacen los criterios de feromonas, en tanto que: a) tienen efectos conductuales inmediatos y no atribuibles a otro estímulo sensorial; b) son sustancias especieespecíficas; c) existe mínima influencia de la experiencia; d) indican el estado social y reproductivo de quien las produce y secreta; y e) las ratas o ratones expuestos al olor de conespecíficos estresados muestran aversión por el origen del olor. El estudio de las señales químicas constituye una herramienta fundamental para investigar los aspectos morfológicos, fisiológicos y bioquímicos de los receptores olfatorios, el mecanismo para el procesamiento de la información odorífera, así como el estudio de las distintas conductas y cambios endócrinos asociados a la comunicación feromonal, todo lo cual hasta hace relativamente poco tiempo se asociaba a ciertas pautas conductuales presentes sólo en los insectos. La evidencia ha indicado con claridad que las feromonas también están presentes en los mamíferos, incluido el humano, un hecho que abre expectativas que aguardan ser exploradas para explicar pautas de comportamiento en prácticamente todas las especies de animales.

(Rev Biomed 2002; 13:189-209)

Palabras clave: feromonas, sistema olfativo, órgano vomeronasal, olores aversivos, roedores.

\section{SUMMARY.}

Etologic aspects of the chemical comunications in rats and mice of laboratory.

Chemical communication through feromones

Solicitud de sobretiros: Dr. Carlos M. Contreras, A.P. 320, Xalapa 91000, Veracruz, México.

Tel:812-57-48_E-mail: cmc@bugs.invest.uv.mx

Recibido el 22/Junio/2001. Aceptado para publicación el 18/Octubre/2001. 


\section{AG Gutiérrez-García, CM Contreras.}

is basic for intraspecific relationships. These substances are particularly important for provoking reproduction, mating, inhibition or induction of aggressive behavior, group and individual recognition, social organization, delimitation of territory, fear and stress, among other behavioral patterns. Diverse studies have determined that the presence of volatile substances in the urine of rats, satisfies feromonal criteria, since: 1) they produce immediate behavioral effects not attributable to any other sensorial stimulus; b) they are species-specific substances; c) there is minimum influence from experience; d) they indicate the social and reproductive state of whoever produces and secretes them; and e) aversion is produced in rats or mice exposed to the odor of their stressed conspecific. The study of the chemical signals constitutes a fundamental tool for the research of morphological, physiological and biochemical aspects of olfactory receptors, the mechanism for the processing of odoriferous information, as well as the study of different behavioral patterns and endocrine changes associated with feromonal communication, which until recently were associated with certain behavioral patterns only displayed by insects. The evidence has clearly indicated that feromones are also present in mammals, including human beings, a fact that leads to expectations remaining to be explored in order to explain behavioral patterns in practically all animal species. (Rev Biomed 2002; 13:189-209)

Key words: Feromones, olfactory system, vomeronasal organ, aversive odors, rodents.

\section{Introducción.}

Las relaciones sociales que se establecen entre individuos de la misma especie o de especies distintas son interdependientes y permiten el intercambio de información mediante complejos sistemas de señalización, con el objeto de satisfacer sus necesidades básicas y asegurar la sobrevivencia tanto de los individuos como de las especies. De manera particular, las señales químicas son útiles en la comunicación intra e interespecífica.

Hace más de cuarenta años, Karlson y Lüscher, después de diversos estudios en insectos, acuñaron el término de feromona para referirse a algunas sustancias químicas que son excretadas al ambiente por un organismo y que tienen como función crear vínculos de comunicación intraespecífica. Este concepto incluye las señales químicas especie específicas, las cuales provocan un comportamiento claro e inmediato; estos compuestos tienen efectos únicos en el sentido de que sus influencias sobre el comportamiento no pueden ser atribuidas a un alertamiento inespecífico (1). Las señales químicas son empleadas no sólo por los animales más primitivos en la escala filogénetica, sino también en los más evolucionados, como los primates, incluyendo al hombre. Tampoco son de dominio exclusivo de los animales; el reino vegetal también las posee, en donde reciben el nombre de fitohormonas.

Generalmente en los estudios que se han llevado a cabo sobre las señales semioquímicas en mamíferos, las feromonas se han implicado en el comportamiento sexual y reproductivo, demostrando por ejemplo, que el olor de un ratón macho puede bloquear la gestación de un ratón hembra, o bien que existen olores que producen sincronización de los ciclos estrales de ratones hembras, lo cual posiblemente explique también la sincronía de los ciclos menstruales en el ser humano $(2,3)$. Sin embargo, existen otras funciones atribuidas a las feromonas, como lo es el reconocimiento específico de individuos de la misma especie o camada, o bien la delimitación del territorio o el nivel jerárquico de dominancia. Asimismo, se ha demostrado la presencia de sustancias que son liberadas en la orina y heces del ratón, las cuales pueden estimular o inhibir la actividad general de otras ratas (4). En otros estudios el origen del olor de ratones estresados ha sido obtenido de glándulas sudoríparas de las patas, piel, o bien, del epitelio respiratorio el cual puede liberar volátiles hacia la sangre o hacia el medio exterior (5) y modificar el comportamiento

\section{Revista Biomédica}


Feromonas y neuroetología.

de los animales que son expuestos a dichos olores. En esta revisión vamos a considerar, brevemente, los sistemas de comunicación química que utilizan principalmente las ratas y ratones estudiados en el laboratorio experimental. Se expondrán algunos ejemplos de los principales comportamientos influenciados por feromonas y su relevancia en las interacciones sociales que se establecen entre individuos de la misma especie, lo cual podría explicar algunas pautas de comportamiento observadas en prácticamente todas las especies de animales, incluido el humano.

\section{Semioquímica.}

Las interacciones y la organización social entre los individuos de una misma especie, se relacionan con la eficacia de los mecanismos de comunicación que utilizan, como por ejemplo la visual, la táctil o la química. De manera particular, la comunicación química es fundamental en las interacciones sociales entre los individuos (6), ya que el olfato constituye un sistema sensorial capaz de afectar de manera directa la fisiología o conducta de otros individuos, por medio de un lenguaje de comunicación determinado por los sentidos químicos. Así, la comunicación animal es un proceso complejo, moldeado filogenéticamente y vinculado al desarrollo anatómico y fisiológico de la especie, de tal manera que un organismo debe ser capaz de diferenciar en un entorno heterogéneo señales relevantes para su sobrevivencia.

A diferentes niveles de la escala evolutiva, el olfato es un sistema sensorial predominante en torno al cual se integran complejas interacciones conductuales determinadas ya sea genéticamente, o bien, adquiridas mediante la experiencia y el aprendizaje, como la búsqueda, la aceptación, o el rechazo de alimento, la predación, las reacciones de huida, el comportamiento sexual y las relaciones sociales, entre otras (7).

Una de las más recientes aproximaciones al estudio del comportamiento social y la comunicación química entre mamíferos, es denominada semioquímica (6). Este término (del griego semeion, señal) se refiere a aquellos compuestos o mezclas de compuestos que poseen información y que median interacciones entre organismos en el medio natural que comparten y que pueden afectar la fisiología y la conducta de los mismos (8). Dentro de las moléculas consideradas quimiosensoriales, las feromonas constituyen sólo una categoría y juegan un papel fundamental en las relaciones etológicas entre los individuos. El término feromona (9) hace referencia específicamente a las interacciones semioquímicas que ocurren entre organismos de la misma especie, los cuales liberan compuestos hacia el ambiente en respuesta a señales químicas y/o físicas (del griego, pherein, transportar, y de la terminación de la palabra hormon, excitar). Son ejemplos de feromonas las sustancias odoríferas que muchos mamíferos depositan con su orina o con secreciones glandulares para marcar su territorio, o bien, para proporcionar información sobre su estado reproductivo. La mayoría de las feromonas son detectadas mediante el olfato, pero algunas otras son ingeridas o absorbidas por medio de la piel (10), la cual contiene una serie de glándulas cuya secreción se encuentra involucrada en la comunicación química de muchas especies de animales incluyendo el humano (11). Es decir, los mamíferos liberan a su medio ambiente una amplia variedad de olores a través de sus productos de excreción, que tienen valor de señalización. En los roedores, por ejemplo, la mayor fuente de feromonas es la orina (12), la cual, dependiendo de su composición y disposición en el ambiente puede actuar como feromona promotora, liberadora o alarmogéna.

Aunque el término de feromona fue inicialmente aplicado e identificado en los insectos, algunos de los estudios más recientes muestran que estos compuestos modifican el comportamiento de diversos organismos, desde los protozoarios hasta el hombre (13). Dentro de la primera clasificación de las feromonas se contaba con aquellas llamadas feromonas liberadoras ("releaser"), las cuales provocan una respuesta primariamente conductual 


\section{AG Gutiérrez-García, CM Contreras.}

instantánea y temporal en otro individuo de la misma especie. Así, existen algunos olores corporales que llevan al animal receptor a evitar o alejarse del sitio donde fue depositada la sustancia; mientras que las feromonas llamadas promotoras ("primer"), pueden ser producidas por uno o más individuos y provocar respuestas lentas que involucran cambios en los estados por ejemplo, endócrinos, en el desarrollo y en el comportamiento.

Años después, en 1968 Bronson (13) propuso el término de señaladores químicos, específicamente para referirse a la comunicación química entre roedores, en lugar del término feromonas liberadoras, ya que sugirió que dicho término denotaba una rigidez conceptual que probablemente no se aplique a los mamíferos, en los cuales las señales químicas son menos claras y las respuestas conductuales no se distinguen de acuerdo a la definición clásica. Estas feromonas de señalización en los roedores han sido relacionadas con la agresión, el apareamiento, el reconocimiento de conespecíficos, el status social, la territorialidad, el cuidado parental y otras funciones vitales durante las interacciones sociales que se establecen entre individuos de la misma especie (12-17). Otro tipo de feromonas que han sido detectadas en los roedores y en otras especies, son las llamadas alarmógenas, las cuales producen respuestas rápidas de excitación general acompañada de comportamientos de escape o de defensa (18).

Como era de esperarse, un compuesto o mezcla de compuestos puede pertenecer a más de una categoría de semioquímicos y actuar como feromona liberadora, promotora o alarmógena. Es decir, en condiciones naturales, las feromonas rara vez son secretadas en ausencia de otras señales sensoriales, y nunca actúan fuera de un contexto ambiental. Por tanto, para que la comunicación química resulte efectiva, es necesario que se encuentren presentes una serie de factores físicos, sociales y ambientales (19). Por ejemplo, dos compuestos ampliamente reconocidos en el ratón macho (Mus domesticus), el dehidro-exobrevicomin y el 2-sec-butil-4,5-dihidrotiazol, han sido implicados tanto en la sincronización del estro y en la aceleración de la pubertad, como en el comportamiento social y agonístico, actuando como inductores de la agresión entre machos; su efecto sobre el comportamiento quizás así depende del contexto social en el que ocurre la exposición semioquímica. Adicionalmente, cada uno de los dos compuestos antes mencionados es biológicamente activo por separado, pero los dos se tornan relativamente más activos cuando se utilizan juntos, es decir, producen un efecto sinérgico sobre el comportamiento $(12,20-22)$.

\section{Química de las feromonas en roedores.}

En los roedores es posible clasificar a las feromonas en función de su estructura química, de sus propiedades físicas, del tipo de glándula y órgano donde son producidas, por la familia biológica donde se encuentran o bien, por su función ya sea conductual o fisiológica. Además, existen algunos mecanismos por medio de los cuales la señal feromonal puede hacerse mucho más específica y efectiva, ya sea ajustando el tiempo de desvanecimiento de la señal, por expansión del espacio activo, mediante el concurso de varias glándulas exócrinas o de una mezcla de feromonas provenientes de la misma glándula, cambiando las condiciones ambientales en que se da e incluso variando la concentración o la duración de la señal (13).

Algunas sustancias como la 2-heptanona y otras cetonas cíclicas de volatilidad semejante, han sido encontradas en muchas especies de insectos. Cuando estos compuestos y sus análogos son bioensayados en cuanto a su capacidad desencadenante de un comportamiento dado, el umbral de percepción -concentración mínimarequerida para inducir una respuesta, está en el orden de $10^{7}$ a $10^{11}$ moléculas por centímetro cúbico de aire. Para ser efectivas y comunicar los riesgos en el momento preciso, estas feromonas de alarma deben: a) ser moléculas volátiles con un

\section{Revista Biomédica}


Feromonas y neuroetología.

peso de 100 a $200 \mathrm{KD}$; b) su espacio de actividad moderadamente pequeño $(10 \mathrm{~cm}) ; y, c)$ su expansión y ocaso, de tan sólo unos minutos (23). De esta manera, alrededor de veinte sustancias elaboradas por insectos se han estimado como feromonas de alarma, se trata de cetonas de 6-8 carbonos o ésteres (24).

La identificación química de los mensajeros químicos en las secreciones, se ha efectuado utilizando la combinación de cromatografía de gases acoplada a espectrometría de masas, como un sistema de gran sensibilidad y alto poder resolutivo (25). La cromatografía de gases representa un medio adecuado para la separación, caracterización y cuantificación de las complejas mezclas orgánicas encontradas en los extractos de tejidos. Esta técnica tiene un gran poder para la separación y estimación de las concentraciones de los componentes de mezclas complejas; mientras que la espectrometría de masas tiene una gran capacidad para la identificación estructural de esos compuestos (6).

Especialmente, la orina del ratón contiene numerosas sustancias volátiles, la unicidad estructural de estas sustancias reside en su actividad óptica la cual a su vez está relacionada con su actividad biológica (17). Esta observación es relevante, dado que una de las hipótesis que intenta explicar la forma en que las sustancias odoríferas actúan en el individuo receptor se establece a través de la teoría molecular o sitio esteroquímico. Es decir, las moléculas estimulantes tienen una forma determinada, la cual se fija dentro de un sitio receptor complementario del órgano olfatorio (teoría de Amoore). Novotny y colaboradores $(12,17)$ han propuesto que la estereoespecificidad de la percepción del olor, depende de la selectividad enantiomera de la feromona, lo cual puede deberse, por ejemplo, a un isomero óptico individual del 3,4dehidro-exo-brevicomin (en presencia de un 2-secbutildihidrotiazol racémico); estas feromonas han sido bioensayadas en pruebas conductuales, demostrándose que ambas actúan sinérgicamente para promover comportamientos sociales y reproductivos (22)

Otros semioquímicos identificados en la orina del ratón, son aquellos que desempeñan un papel relevante como señaladores de dominancia asociada a la agresión y territorialidad (22). El contenido de dos compuestos identificados como terpénicos muestra un incremento dramático en la orina sólo de ratones dominantes, comparado con los subordinados; estas sustancias han sido descritas como a-farneseno y $\beta$-farneseno (20). Estos farnesenos están ausentes en la vesícula urinaria; sin embargo, son los mayores componentes volátiles de la matriz lipidíca de la glándula prepucial del ratón; mientras que el 3,4dehidro-exo-brevicomin y el 2-secbutildihidrotiazol son abundantes en la vesícula urinaria. La combinación de la secreción de la vesícula urinaria y de la glándula prepucial resulta más efectiva para promover la agresividad de los animales dominantes o de aquellos que han sido entrenados para luchar en modelos de agresión (12).

Si bien el origen biosintético de las feromonas no está aún claro, parece existir una similitud estructural entre algunos compuestos aislados e identificados en las plantas y los compuestos volátiles encontrados en la orina de los ratones. Es posible preguntarse, entonces, si existe una cierta secuencia evolutiva de las semejanzas estructurales entre los compuestos hallados en ambas especies, incluyendo a los insectos. Por ejemplo, algunas de las sustancias volátiles que confieren a las plantas y flores gran parte de su fragancia son miembros de los compuestos llamados terpenos. De hecho, el término terpeno es derivado de trementina, un líquido volátil obtenido de los pinos. Además, es reconocido que algunos de estos compuestos excretados por plantas repelen a los insectos y por consiguiente actúan protegiendo a las mismas plantas (26). En el ratón, los farnesenos identificados por Novotny y colaboradores parecen actuar como semioquímicos aversivos para los animales subordinados (22).

Vol. 13/No. 3/Julio-Septiembre, 2002 


\section{AG Gutiérrez-García, CM Contreras.}

El papel que los semioquímicos desempeñan en la comunicación química en diferentes especies de animales posee una significancia biológica relevante para entender muchas pautas de comportamiento, además de la habilidad que posee el órgano vomeronasal para reconocer dichas moléculas y procesar esa información que finalmente desencadenará una respuesta conductual ligada a la comunicación feromonal.

\section{Recepción de las señales químicas.}

La comunicación química involucra tanto la producción como la recepción de las señales químicas (13). En los mamíferos, la percepción sensorial olfatoria está mediada anatómica y funcionalmente por dos distintos órganos sensoriales: el epitelio olfativo principal y el órgano vomeronasal (27). De manera particular, se ha sugerido que las feromonas son detectadas a través del órgano vomeronasal. Este órgano contiene receptores acoplados a la familia de las proteínas G. Cada receptor tiene 7 dominios transmembranales, localizados sobre las microvellosidades de neuronas olfativas sensoriales bipolares, las cuales permiten el análisis molecular de distintas feromonas volátiles y no volátiles (28). Los receptores vomeronasales activan la fosfolipasa, la cual a su vez genera 1,4,5-trifosfato de inositol (IP3) (29). Estos segundos mensajeros abren los canales de $\mathrm{Ca}^{2+} \mathrm{o} \mathrm{Na}^{+}$y modulan los niveles intracelulares libres de $\mathrm{Ca}^{2+}$, todo lo cual promueve la comunicación sináptica desde el axón de la neurona vomeronasal hasta el bulbo olfatorio accesorio (30).

En la rata, la estimulación del órgano vomeronasal con preparados de orina de macho, induce la activación de los subtipos de proteínas G (Gi y Gs), así como una acumulación de IP3 (29); la estimulación con una molécula volátil lipofílica es capaz de activar sólo a las proteínas Gi, en tanto que la activación de la proteína Gs se ve facilitada por la globulina alfa-2, una proteína lipocalina presente en la orina de la rata (31), lo que significa que existen receptores selectivos para cada una de las posibles moléculas odoríferas presentes en la orina de los roedores. Incluso seis feromonas que han sido detectadas en la orina de ratones, como la 2,5 dimetilpirazina, el 2-sec-butil4,5-dihidrotiazol, el 2,3-dehidro-exo-brevicomin, los farnesenos E,E--farneseno y el E, -farneseno, la 2-heptanona- y la 6-hidroxi-6-metil-3-heptanona, provocan respuestas excitatorias sólo en neuronas vomeronasales con lo cual se genera un potencial de acción que se asocia a la entrada de $\mathrm{Ca}^{2+}$. Notablemente, se requiere de una cantidad muy baja del sustrato para activar a los receptores vomeronasales que responden a estas sustancias $\left(10^{-11} \mathrm{M}\right)$, lo cual indica la gran sensibilidad del órgano vomeronasal para detectar feromonas presentes en la orina de ratones (32). De esta manera, se han detectado dos familias de receptores vomeronasales (VIR y V2R) los cuales están acoplados a la familia de las proteínas Gai2 y Gao, respectivamente. Los receptores VIRs se localizan en la porción apical del órgano vomeronasal; mientras que los V2Rs se encuentran expresados en la porción basal de este órgano. Así, se ha sugerido que las señales semioquímicas de la hembra activan preferencialmente a los receptores VIR del ratón macho (29).

Por otro lado, durante mucho tiempo se consideró inexistente el órgano vomeronasal en los humanos (33) y aunque todavía existe incertidumbre de que este órgano en el humano detecte feromonas, es muy posible que esa sea su función. Se han recabado evidencias que indican que el órgano vomeronasal está presente en la mayoría, si no es que en todos los humanos. García-Velasco y Mondragón (34) examinaron la mucosa olfativa de 1000 pacientes durante reconstrucciones quirúrgicas de la nariz y encontraron órganos vomeronasales en todos los casos. Igualmente, Moran y colaboradores (35) reportaron la presencia de residuos vomeronasales en 200 sujetos, hombres y mujeres de diferentes edades y razas. El análisis ultraestructural del órgano vomeronasal realizado en fetos, cadáveres y en pacientes que se sometieron a cirugía plástica,

\section{Revista Biomédica}


Feromonas y neuroetología.

reveló la presencia de dos elementos receptores potenciales que posiblemente constituyen un sistema de detección feromonal en los humanos (36). Por otro lado, la administración de una vomeroferina a humanos sanos, llamada PDD (pregna-4,20-diona-3,6-diona), a concentraciones de $10^{-10}$ a $10^{-8} \mathrm{M}$, decrementa el ritmo de la respiración y de la frecuencia cardiaca, al tiempo que se registra un aumento de las ondas cerebrales alfa del electroencefalograma, indicando que el sujeto se encuentra en un estado de relajación. Además, se observó un decremento significativo de la hormona luteinizante y de la hormona folículo estimulante en el plasma de los sujetos que participaron en dicho estudio (37). Finalmente, Bulger y colaboradores (38) describieron dos genes humanos muy parecidos a los responsables de la síntesis de las proteínas receptoras del órgano vomeronasal de las ratas, el lugar donde se acoplan las feromonas. Asimismo, se ha demostrado que existen ciertos cambios de voltaje en las células del órgano vomeronasal humano, cuando al hombre se le somete a una feromona femenina y viceversa (39). Estos hallazgos permiten suponer la existencia de una posible vía funcional vomeronasal-hipófisis en adultos humanos y se ha sugerido que tal vez sea posible crear medicamentos que tengan un efecto directo sobre el órgano vomeronasal. Al respecto, este grupo de investigadores apoyan la idea de que los compuestos que actúan sobre el órgano vomeronasal podrían algún día emplearse en lugar de los medicamentos que se usan ahora para reducir la testosterona en enfermos de cáncer de próstata, o de los que disminuyen la hormona luteinizante y la testosterona en las mujeres que padecen de ovarios poliquísticos. Asimismo, consideran que el uso de las llamadas vomeroferinas podrían rociarse directamente en el órgano vomeronasal para el tratamiento de trastornos emocionales como la ansiedad generalizada, ya que inducen un estado inmediato de relajación $(37,39,40,41)$. Estas evidencias, soportan la idea de que esta estructura no ha involucionado y muy posiblemente constituya un sistema de comunicación feromonal en los humanos (42).

Efectos de la comunicación feromonal en ratas y ratones estudiados en el laboratorio experimental.

En el ratón doméstico Mus musculus, los mensajeros químicos parecen jugar un papel relevante en el comportamiento social y reproductivo (20). Aunque se ha determinado que esta especie de ratón tiene diferentes fuentes potenciales y conocidas de mensajeros químicos provenientes de diversas glándulas, la orina constituye una de las fuentes de feromonas más rica y estudiada. La sincronización del estro (43), la aceleración de la pubertad (44), el bloqueo de la fecundación (45), el reconocimiento entre grupos e individuos (46), la agresión (47), el miedo y el estrés $(7,14)$, la histocompatibilidad relacionada con la preferencia al apareamiento (48), entre otros, parecen estar bien documentados y relacionados con la orina como una fuente de información química que modula la comunicación intraespecífica en los roedores (20).

\section{Comunicación feromonal en la conducta reproductiva de ratas $\mathrm{y}$ ratones.}

En los ratones han sido descritos fundamentalmente cuatro efectos directamente relacionados con la reproducción, los cuales son facilitados por medio de la orina que actúa a su vez como un vehículo de la feromona promotora y que va a actuar sobre el sistema endócrino del individuo receptor.

Desde hace tiempo se conoce que cuando se alojan juntos cuatro o más ratones hembras, en ausencia de machos, sus ciclos de estro se vuelven irregulares, se reducen y a la larga se detienen. A este fenómeno se le conoce como efecto Lee-Boot (49). Si este grupo de hembras es expuesto al olor de un macho o, específicamente, de su orina, sus ciclos estrales comienzan de nuevo, y tienden además a sincronizarse. A este fenómeno se le da el nombre de efecto Whitten (43). Además, si la 


\section{AG Gutiérrez-García, CM Contreras.}

orina del macho, en una dosis de $0.3 \mathrm{~mL}$ por día durante ocho días es aplicada en la narina de una hembra, el peso de su útero se duplica (50), lo que significa que la comunicación feromonal del macho induce cambios fisiológicos en el sistema reproductivo de la hembra.

Otro fenómeno provocado por feromonas, es el efecto Vandenbergh, que consiste en el aceleramiento del inicio de la pubertad de un ratón hembra inducido por la sola presencia del olor de un ratón macho (43). Incluso, si se les aplican dosis diarias de $0.001 \mathrm{~mL}$ de orina de macho a hembras, se induce aceleración de la pubertad y dicho efecto no se pierde en una dilución de 1:100,000; lo que indica, que la señal química es activa aún a concentraciones muy bajas (51). Por otro lado, el efecto Bruce $(45,52)$ es un fenómeno que tiene lugar cuando una ratona recién preñada encuentra un ratón macho distinto de aquel con el que copuló, entonces es muy probable que sufra una interrupción de la gestación. Este efecto es provocado también por una sustancia presente en la orina de machos intactos pero no en la de aquellos que fueron castrados.

Tanto los efectos Whitten como Vandenbergh son supuestamente provocados por una feromona presente sólo en la orina de los machos adultos intactos, ya que la orina de un macho joven o castrado no tiene estos efectos. Lo que se demostró cuando la feromona aceleradora de la pubertad fue encontrada de nuevo en la orina de machos castrados, 60 h después de la aplicación de $1.0 \mathrm{mg}$ de propionato de testosterona. Asimismo, la orina de ratonas, que normalmente es inactiva, adquiere actividad feromonal cuando son inyectadas con testosterona (53). Pareciera entonces, que la producción de feromonas requiere de la presencia de testosterona. Sin embargo, cuando a ratones machos castrados se les extirpa el órgano vomeronasal no es posible desencadenar los efectos Lee-Boot, Whitten o Bruce a pesar de administrarles propionato de testosterona $(54,55)$, lo que indica claramente la participación del olfato en el proceso.

\section{Revista Biomédica}

En las ratas macho y ratones, la glándula prepucial es la responsable de los olores en la orina que resultan atractivos para las hembras (56-58). Esta glándula es muy sensible a los andrógenos y se dilata de manera sobresaliente cuando se aproxima la madurez sexual (59). Las fracciones lipídicas de las secreciones de la glándula prepucial contienen alquilacetatos, los cuales son atractivos para las ratas hembras; mientras que el dimetildisulfide y el dimetillsulfito, también presentes en extractos de tejido prepucial, son compuestos atractivos sólo para las ratas y ratones macho (6); pero, los ratones hembras gestantes no son atraídos por los olores prepuciales de los machos (60). Esto es de gran relevancia biológica, ya que la orina del ratón macho contiene una feromona promotora, la 2,5-dimetilpirazina, la cual bloquea la fecundación Esta misma sustancia se encuentra ausente en hembras durante la gestación y la lactancia, pero su contenido urinario incrementa significativamente en un grupo de ratonas cuando viven juntas, en ausencia de un macho (16).

\section{Comunicación feromonal en la agresión y territorialidad en ratas y ratones.}

El ratón doméstico macho Mus musculus y otras cepas de ratones como la C57BL/6J se caracterizan por ser extremadamente agresivos y territoriales $(22,61)$. La posibilidad de la conducta agresiva existe siempre y cuando los intereses de dos o más individuos entran en conflicto. La agresividad de un ratón puede ser fácilmente inducida en el laboratorio experimental por medio de un modelo de agresión denominado "intrusoresidente" (61). El procedimiento metodológico empleado en este modelo, consiste en que a uno de los machos se le permite el acceso exclusivo a un territorio de vivienda. El concepto de territorio hace referencia a aquel espacio que el animal ha reservado para sí, en donde se restringe su comportamiento y cuyos límites son rígidamente defendidos contra cualquier "intruso" conespecífico que intente sobrepasarlos (62). Al 
Feromonas y neuroetología.

estudiar colonias de ratones, se ha observado que a pesar de las grandes densidades que llegan a tener las poblaciones de ratones en ciertas áreas, el número de territorios permanece constante, lo cual obliga a los ratones jóvenes a la migración, pues cada territorio usualmente está constituido por varias hembras en edad reproductiva y sus crías, algunos machos subordinados y de un sólo macho territorial dominante sobre todos ellos (63). La comunicación intraespecífica modulada por medio del marcaje urinario tiene funciones potenciales para mantener estos status sociales dentro del grupo así como la interacción entre sus conespecíficos.

Novotny y colaboradores $(12,17,21)$ determinaron la presencia de dos compuestos volátiles, los terpenos E, E-alfa y el E-beta farneseno en la orina de ratones macho dominantes. Al parecer estos dos compuestos desempeñan un papel importante en el marcaje territorial. Los machos subordinados escapan de las secciones del área de un campo abierto que ha sido marcado con estos terpenos provenientes de la orina de un macho dominante. Por lo cual se ha sugerido, que estos farnesenos pueden ser considerados como candidatos semioquímicos urinarios potenciales para modular el comportamiento social y territorial dentro del grupo y muy posiblemente estén actuando como señaladores aversivos para los ratones sumisos o subordinados (22).

El comportamiento del marcaje territorial por medio de la orina parece ser dependiente del status social del macho, de su nivel de testosterona y de un órgano vomeronasal intacto. Por ejemplo, cuando se extirpa el órgano vomeronasal se suprime totalmente la conducta agresiva de los ratones machos forzados a luchar en el modelo intruso-residente (64-66). Asimismo, el comportamiento agresivo es eliminado por la ablación del bulbo olfativo (45), pero se conserva en el ratón al que se le han removido quirúrgicamente los ojos o las vibrisas (46). En consistencia, cuando un grupo de ratas bulbectomizadas son reunidas para vivir en grupo, carecen de respuestas agonísticas espontáneas típicas entre los machos, es decir, no establecen territorialidad, ni luchas ritualizadas en las cuales deben existir los dos componentes etológicos de la agresión, la ofensa y la defensa (67), ya que no despliegan un comportamiento social y no se observan cicatrices en el cuerpo que indiquen el antecedente de peleas para establecer jerarquías (68). Así, la olfación parece jugar un papel crítico en el comportamiento social. En concordancia, se ha determinado un incremento de la actividad del gen que codifica para la proteína $c$-fos en el órgano vomeronasal de animales sometidos a una confrontación social (69), lo que es un indicador de una respuesta local al estrés posiblemente relacionada con el miedo que comúnmente ha sido asociada con la agresión intraespecífica. Por ejemplo, Müller-Valten (14) en 1966 sugirió que los cambios en el olor corporal entre conespecífcos deben ser el resultado de las confrontaciones que tienen en cada contienda (por ejemplo, victoria o derrota); así Carr y colaboradores (14) demostraron que los ratones de la cepa C57BI/6J prefieren olores de un ratón que resulta victorioso en una confrontación que los del perdedor.

Estos resultados indican que la expresión de la agresión y de aquellos comportamientos que la acompañan, son dependientes de la presencia de un sistema vomeronasal intacto modulado por feromonas presentes en la orina de ratones $(12,17)$. En síntesis, existen diversos eventos conductuales (cuadro 1) que son influenciados por feromonas (fig. 1) dependientes de un órgano vomeronasal intacto.

Así, la comunicación feromonal en la conducta reproductiva y social parece estar estrechamente relacionada con los niveles de andrógenos y el status social de los ratones machos $(70,71)$. Lo anterior quedó demostrado cuando un grupo de ratones machos adultos fueron expuestos a otro grupo de ratones entrenados para pelear por un periodo de una semana. La orina de los luchadores entrenados, que en todos los casos fueron dominantes y la de los derrotados (subordinados), 
AG Gutiérrez-García, CM Contreras.

\section{Cuadro 1}

Compuestos químicos con actividad feromonal en ratas y ratones, implicados en conductas reproductivas y sociales dependientes de un sistema vomeronasal intacto.

\begin{tabular}{|c|c|c|c|}
\hline Compuesto* & Origen & Función como señal química & Referencia \\
\hline $\begin{array}{l}\text { 2-Heptanona } \\
\text { 4-Heptatona } \\
\text { 2-Hexanona }\end{array}$ & $\begin{array}{l}\text { Orina de ratones } \\
\text { hembra y machos }\end{array}$ & $\begin{array}{l}\text { Aceleración de la pubertad y prolongación de } \\
\text { la duración del estro (efecto Vandenbergh) }\end{array}$ & $15,16,19,32$ \\
\hline $\begin{array}{l}\text { 2,5-dimetilpirazina } \\
\text { n-pentil acetato } \\
\text { cis-2-acetil penteno }\end{array}$ & $\begin{array}{l}\text { Orina de rata y } \\
\text { ratón hembra }\end{array}$ & $\begin{array}{l}\text { Inhibición de la pubertad en hembras } \\
\text { púberes (Efecto Lee-Boot). }\end{array}$ & 15,19 . \\
\hline $\begin{array}{l}\text { 2-sec-butil-4,5- } \\
\text { dihidrotiazol } \\
\text { 2,3-dehidro-exo- } \\
\text { brevicomin }\end{array}$ & $\begin{array}{l}\text { Vejiga urinaria de } \\
\text { ratones machos }\end{array}$ & $\begin{array}{l}\text { Actúan sinérgicamente para: } \\
\text { a)Promover la agresión entre machos } \\
\text { b) Promover la sincronización del } \\
\text { estro (efecto Whitten) } \\
\text { c) Aceleración de la pubertad } \\
\text { (efecto Vandenbergh) }\end{array}$ & $19,21$. \\
\hline $\begin{array}{l}\text { E-E,-a-farneseno } \\
\text { E-b-farneseno }\end{array}$ & $\begin{array}{l}\text { Glándula prepucial } \\
\text { de ratones machos }\end{array}$ & $\begin{array}{l}\text { Actúan como señales aversivas para el } \\
\text { ratón subordinado, provocando dismi- } \\
\text { nución del husmeo y de la actividad locomotora. } \\
\text { Marcaje territorial } \\
\text { Aceleración de la pubertad (efecto Vandenbergh) }\end{array}$ & $12,19,22,32$ \\
\hline $\begin{array}{l}\text { 6-hidroxi-6-metil- } \\
\text { 3-heptanona }\end{array}$ & $\begin{array}{l}\text { Vejiga urinaria de } \\
\text { ratones machos }\end{array}$ & $\begin{array}{l}\text { Aceleración de la pubertad } \\
\text { (efecto Vandenbergh) }\end{array}$ & 32. \\
\hline $\begin{array}{l}\text { 7-exo-etil-5-metil- } \\
\text { 6,8-dioxabiciclo } \\
\text { [3.2.1]-3-octeno }\end{array}$ & $\begin{array}{l}\text { Orina de ratones } \\
\text { macho (dependiente } \\
\text { de testosterona) }\end{array}$ & $\begin{array}{l}\text { Aceleración de la pubertad } \\
\text { (efecto Vandenbergh) }\end{array}$ & 20. \\
\hline $\begin{array}{l}\text { trans-4-hepten-2-ona } \\
\text { trans-5-hepten-2-ona } \\
\text { Dihidrofuranos } \\
\text { cis-2-penten-1-il } \\
\text { acetato }\end{array}$ & $\begin{array}{l}\text { Orina de ratones } \\
\text { hembras }\end{array}$ & $\begin{array}{l}\text { Asociado al ciclo estral. Incrementan su } \\
\text { concentración en etapa de proestro-estro, } \\
\text { en la gestación y en lactancia. }\end{array}$ & 15,16 \\
\hline 2,5 dimetilpirazina & Orina de hembras & $\begin{array}{l}\text { Se encuentra ausente durante la } \\
\text { gestación y la lactancia y se reduce } \\
\text { significativamente en el estro } \\
\text { (sustancia inhibitoria). }\end{array}$ & 16. \\
\hline
\end{tabular}

*Identificados por métodos de cromatografía de gases acoplada a espectrometría de masas (GC capilar/MS).

fue aplicada en la narina de ratones hembra púberes. Únicamente la orina de los ratones dominantes aceleró el comienzo de la pubertad en las ratonas; mientras que la orina de los ratones subordinados careció de efectos (72). En otro estudio, se clasificó a los machos como dominantes, de segundo y tercer grado, y los subordinados. Igualmente se encontró que la orina de los machos dominantes provocó aceleración de la pubertad; los machos de menor rango tuvieron un efecto intermedio; y la orina de los machos subordinados no tuvo efecto para provocar el comienzo de la pubertad en las

\section{Revista Biomédica}


Feromonas y neuroetología.

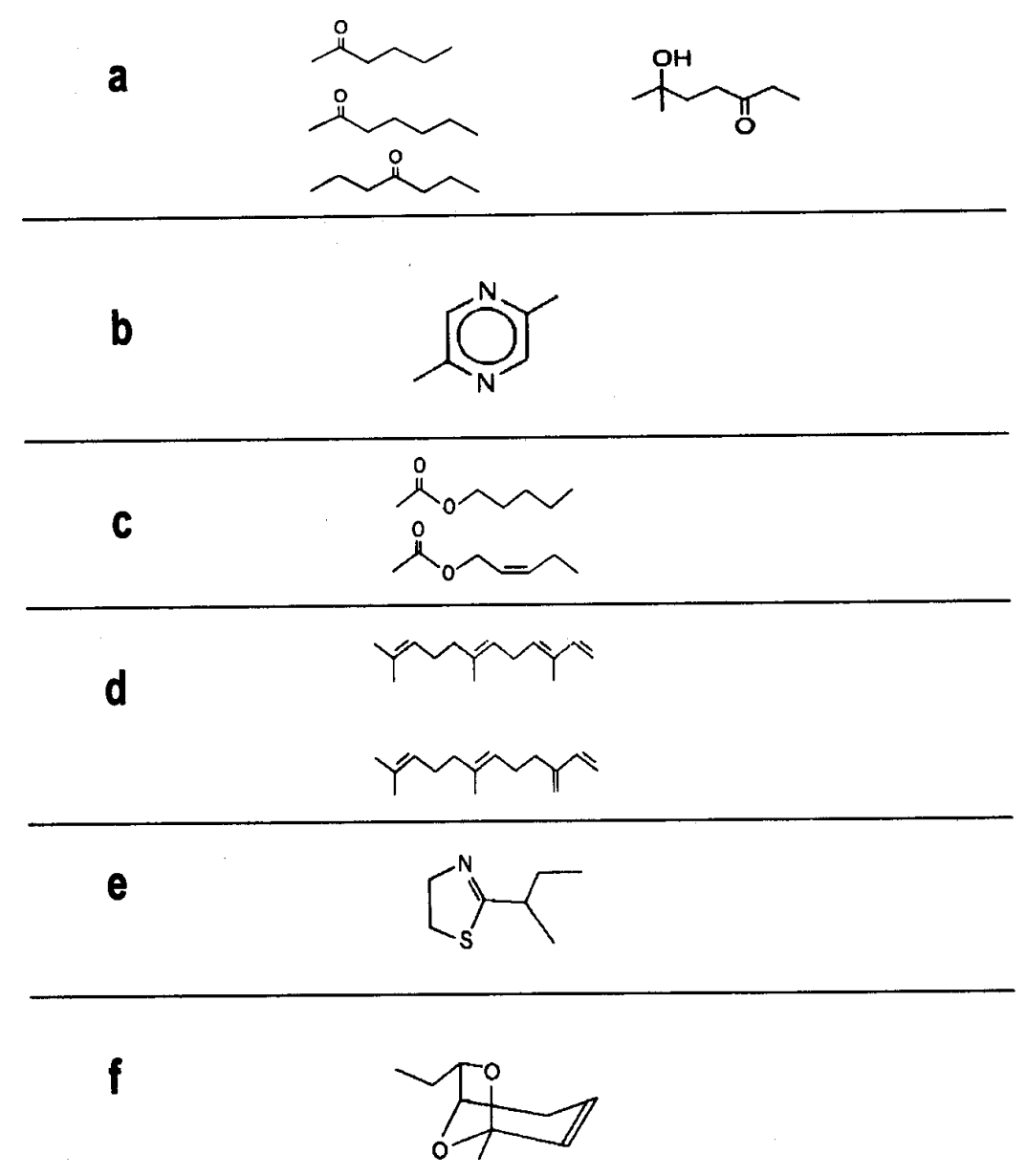

Figura 1.- Estructura química de algunos de los compuestos urinarios que poseen actividad semioquímica en el ratón (para mayor información, ver 19). Se han identificado algunas cetonas como: a) 2-hexanona, 2-heptanona, 4-heptanona y 6-hidroxi-6-metil-3-heptanona; b) pirazinas como la 2,5-dimetilpirazina; c) ésteres como: $n$-pentil acetato, cis-2-pen1-yl acetato; d) algunos terpenos como: E-E-a-farneseno y E-b-farneseno; e) tiazoles como el 2-sec-4,5-dihidrotiazol; y f) otros como el 3,4-dehidro-exo-brevicomin.

hembras (73). Al respecto, se ha demostrado que las hembras tienden a evitar aquellas áreas donde se localizan los ratones subordinados o no agresivos, exhibiendo preferencias por deposiciones de ratones agresivos o dominantes; mientras que los machos tienden a evitar olores de ratones no agresivos (74). Esto sugiere que los semioquímicos relacionados con el comportamiento agresivo y la capacidad sexual, están relacionados con el funcionamiento testicular; mismos que las hembras detectan por medio de la olfación, lo cual influye decisivamente en sus preferencias y probablemente en la elección de un compañero sexual.

Los efectos de los factores sociales sobre los ciclos ováricos no están limitados a los ratones. Es probable que también el olfato sea un componente importante en la conducta sexual humana. Existe al menos un informe clínico sobre mujeres con ausencia congénita de bulbos olfatorios que reveló una incidencia notablemente superior de hipoplasia ovárica (75). Otro síndrome llamado de Kallman, que se presenta principalmente en hombres, se caracteriza por hipogonadismo hipogonadotrópico acompañado de anosmia (76). Estos sujetos son estériles y en su caso, su déficit 


\section{AG Gutiérrez-García, CM Contreras.}

sensorial no resulta afectado directamente por las hormonas, sino más bien por una afección congénita que bloquea el desarrollo normal tanto de los bulbos olfatorios como de la función endocrina.

En tanto que, las mujeres que viven juntas durante periodos prolongados a la larga sincronizan sus ciclos menstruales, aquellas que pasan un tiempo regular en presencia de hombres tienden a tener ciclos menstruales más breves que aquellas que pasan menos tiempo con hombres (2). De manera particular, los estímulos sociales, especialmente los que se perciben como estresantes, pueden influir en los ciclos menstruales de las mujeres. Por ejemplo, los eventos que producen tensión, desde el inicio de cursos estudiantiles al encarcelamiento, pueden asociarse a la suspensión de los ciclos menstruales (77). Así, un estudio de mujeres premenopáusicas condenadas a muerte en espera de la ejecución, se comprobó que no experimentaban ciclos menstruales (78). Estas observaciones, sugieren que durante situaciones estresantes se emiten estímulos que son percibidos por medio del olfato, los cuales desencadenan alteraciones en las funciones fisiológicas y como consecuencia cambios en el comportamiento.

\section{Comunicación feromonal de alarma en ratas de laboratorio.}

Otras funciones que se le han atribuido a las feromonas en roedores sugieren que el olor de las ratas de laboratorio, puede influir en la ejecución de las pruebas conductuales que se emplean en diversos paradigmas de aprendizaje. Por ejemplo, los olores liberados por las ratas durante las fases de recompensa y de extinción en experimentos de aprendizaje pueden interferir con la ejecución de otro animal subsecuente (79). Morrison y Ludvingon (80), trabajando con ratas en un laberinto en "T", lograron que la elección dependiera de la capacidad para discriminar un aroma de reforzamiento o de no reforzamiento en el punto de la elección. Si el olor -de existir- es un estímulo discriminativo, el animal debería escoger un corredor particular del laberinto cuando el olor estuviera presente y recibir reforzamiento por ello. Los resultados indicaron que solamente aquellos grupos que tuvieron el olor de ausencia de recompensa como indicador, mostraron aprendizaje por discriminación. Al parecer la ausencia de reforzamiento tiene asociado consigo un olor distintivo que el reforzamiento no tiene. Además, parece que el olor del no reforzamiento es aversivo, y los animales procuran evitarlo. Collerain y Ludvigson (81) llevaron a cabo una serie de experimentos que demostraron que las ratas aprenden a escapar de un compartimento en el que otra rata ha experimentado ausencia de reforzamiento, por lo que dieron el nombre de "aroma de frustración" al olor que se produce durante el no reforzamiento, el cual quizá pueda tratarse de un señalador químico aversivo.

Para que estas sustancias sean reconocidas como señaladores aversivos es necesario que exista un reconocimiento entre individuos, que también es mediado por señales químicas. Se ha demostrado que los animales aprenden a temprana edad a discriminar olfativamente las características de sus conespecíficos de una manera análoga a lo que sería la impresión visual (82). Todrank y colaboradores (83), han sugerido que las interacciones sociales entre los individuos que forman un grupo son necesarias para discriminar olores entre individuos conocidos. Luego entonces, los ratones forman una imagen química que incluye la distribución espacial y ambiental de sustancias químicas para la transferencia de información entre sus conespecíficos (6), lo cual sugiere que existe una sensibilización del sistema olfatorio a los olores propios de la especie; de esta manera el adulto puede reconocer el sexo y el parentesco con otro sujetos e incorporar en las señales que permiten este reconocimiento otro tipo de pistas tales como las vocalizaciones ultrasónicas y algunas pautas conductuales.

Uno de los descubrimientos más reconocidos con relación a las señales químicas es que los

\section{Revista Biomédica}


ratones de cepas consanguíneas pueden discriminar olores de ratones que difieren genéticamente en una región cromosomal ocupada por genes que también codifican para el sistema inmune (48). Es decir, el olor que desprende un animal esta determinado en parte por sus genes. Este complejo de genes, conocido como Complejo Mayor de Histocompatibilidad, no sólo comparte funciones inmunológicas importantes para el reconocimiento de la superficie de la célula en desarrollo (84), si no también la fuente de información quimiosensorial presente en la orina que permite a los ratones identificar a uno u otro como individuo (85). Esto es, aquellos ratones que difieren genéticamente sólo en una región cromosómica implicada en funciones inmunológicas, se reconocen unos a otros por el olor, lo que significa que los genes de histocompatibilidad confieren un olor característico y por tanto, permiten el reconcimiento y enriquecimiento del acervo genético, así como el reconocimiento de señales especie-específicas. Hayashi y Kimura (86) han mostrado que en ratones el aprendizaje infantil de los olores está asociado a la evitación del incesto, es decir, las hembras eluden aparearse con machos que huelan como sus padres o hermanos. Entonces, los olores determinados por los genes del complejo mayor de histocompatibilidad juegan un papel importante en las interacciones familiares en muchas especies, incluyendo el humano. La investigación reciente ha demostrado el papel que estos genes desempeñan para el reconocimiento madre-infante en los humanos, lo cual en parte está mediado por la olfación. Además de que existe el reporte de antecedentes de abortos recurrentes espontáneos en parejas que comparten antígenos del complejo mayor de histocompatibilidad $(85,87)$.

Así mismo, es reconocido que las ratas liberan de manera innata olores que son reconocibles para sus conespecíficos en respuesta a una variedad de eventos aversivos naturales y no naturales $(88,89)$; por ejemplo, en respuesta a choques eléctricos en las patas, las ratas liberan olores que sus conespecíficos son capaces de discriminar de aquellos olores de ratas no estresadas (90). Las ratas de la cepa Sprague-Dawley, cuando son expuestas a olores de ratas estresadas por choques eléctricos en las patas, despliegan reacciones de evitación y tienen mayor preferencia por los olores de conespecíficos no estresados (91). Así mismo, los ratones de la cepa $\mathrm{C} 57 \mathrm{BI} / 6 \mathrm{~J}$ prefieren los olores de ratones que no han sido estresados con choques eléctricos en las patas pero no es así con un ratón que recibió 10 choques $(1 \mathrm{~mA}, 5 \mathrm{seg})$ durante 5 min, en un periodo de diez días consecutivos (14). En este mismo sentido, Fanselow (92), demostró que en las ratas que son expuestas a olores de ratas que recibieron choques eléctricos en las patas, se produce analgesia que es revertida por la administración de naloxona, un antagonista no específico a receptores a opiodes; así, estos mecanismos analgésicos endógenos son activados como parte del componente defensivo de los sistemas motivacionales de protección ante eventos aversivos.

Recientemente, se ha demostrado que la producción de opioides endógenos en el sistema nervioso es particularmente sensible a las influencias feromonales (93). Los opioides tienen un papel importante en la modulación inmune, y al parecer la exposición a los olores de animales estresados induce la secreción de opioides endógenos, acompañada por un incremento en las respuestas antígeno-anticuerpo. Por ejemplo, los ratones $\mathrm{BALB} / \mathrm{c}$ expuestos a olores emanados por ratones estresados por medio de choques eléctricos en las patas incrementan las respuestas de anticuerpos y la producción esplénica de interleucina (IL)-4 después de la inmunización con células $\mathrm{T}$ dependientes de antígeno en comparación con los ratones expuestos a olores de conespecíficos que no fueron estresados (94). Cocke y Thiessen (95) concluyeron al respecto, que los olores emanados de ratas estresadas por choques eléctricos en las patas, incrementan la actividad del eje hipotálamo-hipófisis-adrenal de las ratas conespecíficas expuestas a dicho olor, este incremento a su vez suprime la función inmune, 


\section{AG Gutiérrez-García, CM Contreras.}

inhibiendo la producción de interleucina (IL)-2 y la proliferación de linfocitos T. Estos estudios explican el porque los ratones que son expuestos a olores de conespecíficos estresados son más vulnerables a sufrir enfermedades atribuidas a condiciones de estrés prologado y constituyen un modelo para el estudio del estrés psicosocial en roedores (96).

Con estas evidencias, de manera general, podemos considerar a las sustancias bioquímicas de intercomunicación que advierten de un riesgo o informan de un peligro, como alarmógenas ya que tienen un efecto directo, inmediato y reversible en el comportamiento de otros individuos de la misma especie y pueden producir, entre otros, cambios endócrinos y evocar un comportamiento defensivo y evasivo ante un enemigo en potencia. Este tipo de comunicación de alarma ha sido observado principalmente en los insectos (31), en ciertos peces (7) e incluso en las lombrices (97). Las feromonas de alarma tienen una gran trascendencia para los insectos sociales, ya que estas sustancias les comunican la presencia de un peligro (28), por ejemplo.

Una evidencia clásica demostrativa de la existencia de las citadas sustancias, la debemos a las experiencias de Karl von Frisch (24) con un pez, Phloxinus leavis, el cual al separarlo de un banco normal comunitario, se le lesionó ligeramente, y al intentar retonarle a su comunidad, se observó dispersión del grupo, posiblemente por la simple presencia del herido. En una serie de observaciones, Frisch demostró que el estímulo de dispersión en Phloxinus es una sustancia hidrosoluble, llevada por las aguas y que la intensidad dispersiva -es decir la respuesta a la señal bioquímica- varía con la concentración de la misma y también con el estado fisiológico del receptor.

Aunque Von Frisch fue el primero en describir una sustancia de alarma en el pez y posteriormente otros estudios llevados a cabo en insectos indicaron la presencia de este tipo de sustancias, en los mamíferos ha sido poco explorado. Causa sorpresa la escasez de estudios críticos disponibles sobre la presencia y caracterización química de las feromonas de alarma en los mamíferos, tanto más cuando el comportamiento evasivo en muchas especies se conoce desde antaño y se le induce con relativa facilidad, haciendo posible un ensayo bioquímico específico (24).

Los primeros estudios relacionados con las sustancias de alarma en ratas y ratones son los de Müller-Velten (14) que muestran como el ratón puede evitar áreas o compartimentos que aún tengan el olor de animales que hayan sido estresados y prefieren áreas que no contengan aromas. Los ratones despliegan una reacción de huida en respuesta al olor de conespecíficos estresados, pero no del de otras especies. Asimismo, cuando un área ha sido impregnada con la orina de una rata estresada, continúa evocando una reacción de huida por otros animales de la misma especie, inclusive varias horas después. Existen otras evidencias de que la orina de un ratón estresado es suficiente para causar en un ratón de prueba la elección de una vía no olorosa $(7,91)$ e incluso las ratas albinas son capaces de discriminar entre el olor de una rata estresada por choques eléctricos en las patas del de otras no estresadas (90).

Por otra parte, las ratas estresadas emiten olores que pueden estimular o inhibir la actividad general de otras ratas $(4,98,99)$. Por ejemplo, Abel y Hannigan (100), han sugerido la existencia de feromonas de alarma en la prueba de nado forzado. Cuando las ratas son forzadas a nadar, emiten una conduca de inmovilidad, la cual ha sido interpretada como una conducta de desesperanza, ya que las pautas conductuales indicadoras de la búsqueda de una salida, bien pueden considerarse como un indicador del estado motivacional de los animales para resolver una situación de apremio (101). Así, la inmovilidad se reduce cuando los animales son pretratados con fármacos antidepresivos como los tricíclicos, los inhibidores de la monoaminooxidasa, los antidepresivos atípicos, e incluso con los tratamientos no farmacológicos como el electrochoque (101-104). En la prueba de nado

\section{Revista Biomédica}


Feromonas y neuroetología.

forzado, las ratas exhiben un decremento en la inmovilidad cuando no se cambia el agua del estanque entre una prueba y otra, es decir entre una rata y otra (105). Abel y colaboradores $(1,100$, 105) suponen la existencia de una feromona de alarma, cuyo concepto incluye aquellas señales químicas especie-específicas las cuales propician un comportamiento claro e inmediato, con un mínimo de la experiencia y cuyos efectos no se deben a un alertamiento inespecífico. Este grupo apoya la idea de que la inmovilidad en la prueba de nado forzado, más que representar una desesperanza conductual constituye una respuesta de afrontamiento al estrés, ya que cuando las ratas han pasado por una sesión de estrés previa al nado forzado, por choques en las patas o por ruido intenso, la inmovilidad tiende a decrementar (105), lo que ha sido interpretado como una alta reactividad o miedo (1). Por lo tanto, la disminución de la inmovilidad en las ratas que nadan en un estanque donde previamente han nadado otras, puede deberse a un estado de ansiedad o miedo favorecido por la presencia de una sustancia de alarma de baja volatilidad presente en el agua (1). El incremento de la actividad observada en la prueba de nado forzado no parece constituir una respuesta exploratoria, sino una respuesta de escape, similar a la respuesta de huida que exhiben los animales que son sometidos a otros contextos en donde están presentes feromonas de alarma (106), por ejemplo, las respuestas de escape que exhiben las ratas cuando se les introduce en un área que previamente fue ocupada por ratas estresadas por choques eléctricos en las patas $(5,7$, 18, 106).

\section{Comentarios y conclusiones.}

En ratas y ratones, se han bioensayado e identificado estructuralmente una gran cantidad de sustancias, algunas de ellas de naturaleza volátil, que tienen como función mediar la comunicación química entre individuos de la misma especie. Así, se les ha involucrado en la agresión, en el apareamiento y la reproducción, en la identificación entre grupos y entre individuos, en la organización social, en el marcaje territorial, en respuestas de huída ante situaciones aversivas, entre muchas otras conductas. Estas sustancias químicas no sólo están presentes e influencian la vida de los roedores, sino también al parecer la del hombre. Si bien, aún no existen muchas evidencias que indiquen que el órgano vomeronasal humano en realidad cumpla funciones fisiológicas importantes, su presencia en la cavidad nasal sugiere una actividad biológica.

En la actualidad se conoce la ultraestructura de la mucosa olfativa y su excepcional morfología, la cual ha sido estudiada, incluso mediante microscopía electrónica. Sin embargo, cuando se realiza un balance de los conocimientos sobre la integración de la información olfativa en el sistema nervioso central aún resulta incompleto, pues aún es difícil relacionar los estudios moleculares y electrofisiológicos con el comportamiento (107). Sin embargo, a pesar de estas limitaciones es importante reconocer que la fisiología de la olfación ha sido un modelo para el estudio de los numerosos sistemas sensoriales. Además, la entrada olfatoria fue una de las primeras vías de acceso conocidas para el sistema límbico, la base orgánica de nuestras emociones. Y si bien, hoy en día se sabe que muchas de las estructuras que conforman el llamado rinencéfalo (la amígdala, el hipocampo, la corteza entorrinal y la corteza pericallosa), todas ellas tienen funciones de integración multisensorial y no sólo la olfación (107); no obstante, existen evidencias de que muchos comportamientos muy primitivos como la conducta sexual, la agresión, la furia y la huída están mediados por sustancias químicas odoríferas que necesariamente tienen su recepción en el sistema olfativo para después ser procesadas por estructuras límbicas que modulan estos comportamientos. Cabe mencionar que el sistema olfativo tiene proyecciones importantes directas hacia el sistema límbico y pocas hacia la neocorteza, es decir, la comunicación olfativa existe, aún, cuando no nos demos cuenta, lo cual sugiere que una variedad de sustancias odoríferas pueden estar asociadas a muchos estados afectivos 


\section{AG Gutiérrez-García, CM Contreras.}

en todos los animales incluyendo al hombre.

Estos estudios explicarían en parte, por qué en la orina y en la piel del humano se han encontrado compuestos que podrían estar desempeñando un papel importante en la comunicación feromonal y en los estados afectivos. Un ejemplo claro lo constituyen algunas anormalidades metabólicas que modifican el olor del cuerpo y de la orina. Esta alteración conocida como "síndrome del olor a pez", provoca un olor extremadamente aversivo y desagradable para los individuos que rodean al paciente, quienes los rechazan socialmente. Muchas de éstas personas mueren, no por su alteración metabólica, sino por las reacciones psicosociales que el olor les provoca, al grado de que muchos de ellos han llegado al suicidio (108). Asimismo, existen casos que demuestran cómo algunas patologías como la esquizofrenia y la depresión, principalmente la de tipo endógeno, están asociadas con una alteración conocida con el nombre de "síndrome derilante olfatorio" (109). Las ideas delirantes y alucinaciones olfativas desagradables que experimentan estos pacientes se exacerban en situaciones sociales, las cuales son revertidas cuando se administran tratamientos combinados de fenotiazinas con antidepresivos tríciclicos como la imipramina. Se reconoce que ambos trastornos son biológicamente heterogéneos y se desconocen diversos aspectos de su fisiopatología; sin embargo, en ambos existen alteraciones que involucran a varios sistemas de neurotransmisión y estructuras límbicas, por lo que la esfera afectiva se encuentra gravemente alterada.

Por último, a pesar de que la aromaterapia es cuestionada, la historia guarda una infinidad de anécdotas donde los olores tienen un papel importante. Es sabido desde los tiempos de los griegos, que Teofrasto, considerado como el primer aromaterapeuta, escribió un tratado de lo "relativo a los olores", en el cual analizaba los efectos de los distintos aromas sobre el pensamiento, el sentimiento y la salud. Otro ejemplo es JeanBaptiste Grenouille, el protagonista del libro "El perfume", quien se obsesiona por lograr el aroma ideal que hechizará a la humanidad. Un relato que hace despertar las sensaciones olfativas más desagradables y agradables, sugestionando al lector; o el "mundo feliz" de Huxley, quien describe una atmósfera de aromas de bienestar y relajación para sus habitantes.

Hemos revisado algunas de las explicaciones científicas sobre la química que producen los olores en las ratas y ratones de laboratorio, pero aún es motivo de estudio su participación en el mundo sensorial del humano, él cual ha sido sometido al imperio de las imágenes y los sonidos, donde uno de los sentidos más primitivos, como lo es el olfato, ha quedado muchas veces relegado.

\section{AGRADECIMIENTOS.}

Se agradece a Irene Marquina por revisar el resumen en el idioma inglés. Asimismo, AGG-G recibió una beca para estudios de Posgrado del Consejo Nacional de Ciencia y Tecnología (CONACyT), con registro 150023, así como un apoyo parcial de la Dirección General de Estudios de Posgrado de la Universidad Nacional Autónoma de México (DGEP-UNAM).

\section{REFERENCIAS.}

1.- Abel EL. Alarm substance emitted by rats in the forcedswim test is a low volatile pheromone. Physiol Behav 1991; 50:723-7.

2.- McClintock MK. Menstrual synchrony and suppression. Nature 1971; 229:224-45.

3.- McClintock MK. On the nature of mammalian and human pheromones. Ann N Y Acad Sci 1998; 855:390-2.

4.- Zalaquett C, Thiessen D. The effects of odors from stressed mice on conspecific behavior. Physiol Behav 1991; 50:221-7.

5.- MaCkay-Sim A. The sources of odors from stressed rats. Physiol Behav 1981; 27:511-3.

6.- Albone ES. Mammalian semiochemistry. The investigation of chemical signals between mammals. Chichester (New York): John Wiley \& Sons; 1984.

7.- Rottman SJ, Snowdon CH. Demonstration and analysis 
Feromonas y neuroetología.

of an alarm pheromone in mice. J Comp Physiol Psychol 1972; 81:483-90.

8.- Regnier FE. Semiochemicals-structure and function. Biol Reprod 1971; 4:309-26.

9.- Karlson P, Lüsher M. "Pheromones" a new term for a class of biologically active substances. Nature 1959; 183:556.

10.- Carlson N. Fundamentos de Psicofisiología Fisiológica. 3a. ed. México: Prentice-Hall Hispanoamericana; 1996. p. 376-7, 394-405.

11.- Müller-Schwarze D. Scent glands in mammals and their functions. En Eisenbergh JF, Kleiman DG, editores. Advances in the study of mammalian behavior. Washington: American Society of Mammalology; 1983. p. 150-97.

12.- Novotny M, Harvey S, Jemiolo B. Chemistry of male dominace in the house mouse, mus domesticus. Experientia 1990; 46:109-13.

13.- Vanderbergh JG. Pheromones and mammalian reproduction. En Knobil E, Neil JD, editores. The Physiology and reproduction. 2nd. ed. New York: Raven Press; 1994. p. 343-56.

14.- Carr WJ, Martorano RD, Krames L. Responses of mice to odors associated with stress. J Com Physiol Psychol 1970; 71:223-8.

15.- Schwende FJ, Wiesler D, Novotny M. Volatile compounds associated with estrus in mouse urine: potential pheromones. Experientia 1984; 40: 213-5.

16.- Andreolini F, Jemiolo B, Novotny M. Dynamics of excretion of urinary chemosignals in the house mouse (Mus musculus) during the natural estrous cycle. Experientia 1987; 43:998-1002.

17.- Novotny MV, Xie TM, Harvey S, Wiesler D, Jemiolo B, Carmack M. Stereoselectivity in mammalian chemical communication: male mouse pheromones. Experientia 1995; 51:738-43.

18.- King MG, Pfister HP, DiGiusto EL. Differential preferences for and acctivation by the odoriferous compartment of a shuttlebox in fear conditioned and naive rats. Behav Biol 1975; 13: 175-81.

19.- Novotny M, Jemiolo B, Harvey S. Chemistry of rodent pheromones: molecular insights into chemical signalling in mammals. En MacDonald DW, Müller-Schwarze P, Natynczuk SE, editores. Chemical signals in vertebrates. Oxford: Oxford University Press; 1990. Vol. 5:1-22.

20.- Novotny M, Schwende FJ, Wiesler D, Jorgenson JW, Carmack M. Identification of a testosterone-dependent unique volatile constituent of male mouse urine: 7 exoetil-5-metil-6,8-dioxabiciclo(3.2.1(-3-octano. Experientia 1984; 40:217-20.

21.- Novotny M, Harvey S, Jemiolo B, Alberts J. Synthetic pheromones that promote inter-male aggression in mice. Proc Natl Acad Sci USA 1985; 82:2059-61.

22.- Jemiolo B, Xie TM, Novotny M. Urine marking in male mice: responses to natural and synthetic chemosignals. Phisiol Behav 1992; 52:521-6.

23.- Wilson DE, Bossert WA. Chemical communication among animals. Recent Prog Horm Res 1963; 19:673-710.

24.- Verdejo-Vargas G. Las Feromonas. México: Almaria; 1978.

25.- Darbio AK. Cromatografía de gases II. España: Alhambra; 1973.

26.- Pine HS, Hendrickson JB, Cram DJ, Hammond GS. Química orgánica. 2a ed. México: McGraw-Hill; 1993. p.892-8.

27.- Liman ER, Corey DP, Dulac C. TRP2: A candidate transduction channel for mammalian pheromone sensory signalling. Proc Natl Acad Sci USA 1999;96:5791-6.

28.- Dulac C. Molecular biology of pheromone perception in mammals. Semin Cell Dev Biol 1997; 8:197-205.

29.- Keverne EB. The vomeronasal organ. Science 1999; 286:716-20.

30.- Shipley MT, McLean JH, Ennis M. Olfactory System. En Paxinos G, editor. The rat nervous system. New York: Academic Press; 1995. p. 899-926.

31.- Krieger J, Heinz B. Olfatory reception in invertebrates. Science 1999; 286:720-3.

32.- Leinders-Zufall, Lane AP, Puce AC, Ma W, Novotny M, Shipley MT, Zufall F. Ultrasensitive pheromone detection by mammalian vomeronasal neurons. Nature 2000; 405:792-6.

Vol. 13/No. 3/Julio-Septiembre, 2002 


\section{AG Gutiérrez-García, CM Contreras.}

33.- Crosby EC, Humphrey T. Studies of the vertebrate telencephalon. I. The nuclear configuration of the olfactory and accessory olfactory formation and of the nucleus olfactorius anterior of certain reptiles, birds, and mammals. J Comp Neurol 1938; 71:121-213.

34.- García-Velasco J, Mondragon M. The incidence of the vomeronasal organ in 1000 human subjects and its possible clinical significance. J Steroid Biochem Mol Biol 1991; 39:561-3.

35.- Moran DT, Jafek BW, Rowley JC. The vomeronasal (Jacobson's) organ in man: ultrastructure and frequency of occurrence. J Steroid Biochem Mol Biol 1991; 39: 54552.

36.- Stensaas LJ, Lavker RM, Monti-Bloch L, Grosser BI, Berliner DL. Ultrastructure of the human vomeronasal organ. J Steroid Biochem Mol Biol 1991; 39:553-60.

37.- Berliner DL, Monti-Bloch L, Jennings-White C, DíazSanchez V. The functionality of the human vomeronsal organ (VNO): evidencie for steroid receptors. J Steroid Biochem Mol Biol 1996; 58:259-65.

38.- Bulger M, Von Doorninck JH, Saitoh N, Telling A, Farrell C, Bender MA, et al. Conservation of sequence and structure flanking the mouse and human -globin loci: the globin genes are embedded within an array of odorant receptor genes. Proc Natl Acad Sci USA 1999; 96:512934.

39.- Monti-Bloch L, Díaz-Sánchez V, Jennings-White C, Berliner D. Modulation of serum testosterone and autonomic functions through stimulation of the male human vomeronasal organ (VNO) with pregna-4,20-diene3,6-dione. J Steroid Biochem Mol Biol 1998; 65:237-42.

40.- Grosser BK, Monti-Bloch L, Jennings-White C, Berliner DL. Behavioral and electrophysiological effects of androstadienone, a human pheromone. Psychoneuroendocrinology 2000; 25:289-99.

41.- Monti-Bloch L, Grosser BI. Effect of putative pheromones on the electrical activity of the human vomeronasal organ and olfactory epithelium. J Steroid Biochem Mol Biol 1991; 39:573-82.

42.- Zbar RI, Zbar LI, Dudley C, Trott SA, Rochrich RJ, Moss RH. A classification schema for the vomeronasal organ in Humans. Plst Reconstr Surg 2000; 105:1284-8.
43.- Whitten WK. Ocurrence of anestrus in mice caged in groups. J Endocrinol 1959; 18:102-7.

44.- Vandenbergh JG, Witsett JM, Lombardi JR. Partial isolation of a pheromone accelerating puberty in female mice. J Reproduc fertill 1975; 43:515-23.

45.- Bruce HM. A block to pregnancy in the mouse caused by proximity of strange males. J Reproduc fertill 1960; 1:96103.

46.- Ropartz P. The relation between olfactory stimulation and aggressive behaviour in mice. Anim Behav 1968; 16:97-100.

47.- Archer J. The effect of strange male odor on aggressive behavior in male mice. J Mammalogy 1968; 49:572-5.

48.- Yamazaki K, Boyse EA, Mike V. Control of mating preference in mice by genes in the major histocompatibility complex. J Exp Med 1976; 144:1324-30.

49.- Van der Lee S, Boot LM. Spontaneous pseudopregnancy in mice. Acta Physiol Pharmacol Néerland 1955; 4:442-4.

50.- Vandenbergh JG, Coppola D. The physiology and ecology of puberty modulation by primer pheromones. En Rosenblatt JS, Beer C, Busnel M, editores. Advances in the Study of Behavior. New York: Academic Pres; 1986. p. 71-107.

51.- Drickamer LC. Effects of very small doses of urine on acceleration and delay of sexual maturation in female house mice. J Reprod Fertil 1984; 71: 475-7.

52.- Bruce HM. Further observations of pregnancy block in mice caused by proximity of strange males. J Reprod fertill 1960; 2:311-2.

53.- Lombardi JR, Vandenbergh JG, Whitsett JM. Androgen control of the sexual maturation pheromone in house mouse urine. Biol Reprod 1976; 15:179-86.

54.- Rowe FA, Edwards DA. Olfatory bulb removal: influences on the aggressive behavior of male mice. Physiol Behav 1971; 7:885-90.

55.- Halpern M. The ortanization and function of the vomeronasal system. Annu Rev Neurosci 1987; 10:32562.

56.- Bronson FH, Carrom D. Preputial gland of the male

\section{Revista Biomédica}


Feromonas y neuroetología.

mouse: attractant function. J Reprod Fertil 1971; 25:27982.

57.- Gawienowski A. Chemical attractants of the rat preputial gland. En Müller-Schwarze D, Mozell MM, editores. Chemical signals in vertebrates. New York: Plenum Press; 1977. p. 45-60.

58.- Gawienowski AM, Orsulak PJ, Stacewicz-Sapuntzakis M, Joseph BM. Presence of sex pheromone in preputial glands of male rats. J Endrocrinol 1975; 67:283-8.

59.- Ebling FJ. Hormonal control of mammalian skin glands. En Müller-Schwarze D, Mozell MM, editores. Chemical signals in vertebrates. New York: Plenum Press; 1977. p. 17-33.

60.- Marchlewska-Koj A. Pregnancy blocking by pheromones. En Vanderbergh JG, editor. Pheromones and Reproduction in Mammals. New York: Academic Press; 1983. p. 151-73.

61.- Blanchard DC, Blanchard RJ. The colony model of aggression and defense. En Dewsbury DA, editor. Contemporary issues in comparative psychology. Sunderland, Massachusetts: Sinauer Associates, Inc; 1991. p. $410-30$.

62.- Hinde RA. Bases biológicas de la conducta social humana. México: Siglo XXI; 1977. p. 259-302.

63.- Poole TB, Morgan HDR. Social and territorial behaviour of laboratory mice (Mus musculis L.) in small complex areas. Anim Behav 1976; 24:476-80.

64.- Clancy AN, Coquelin A, Macrides F, Gorski RA, Noble EP. Sexual behavior and aggression in male mice: involvement of the vomeronasal system. J Neurosci 1984; 4:2222-9.

65.- Maruniak JA, Wysocki CJ, Taylor JA. Mediation of male mouse urine marking and aggression by the vomeronasal organ. Physiol Behav 1986; 37:655-7.

66.- Guillot PV, Chapouthiera G. Olfaction, GABAergic neurotransmission in the olfactory bulb, and internal aggression in mice: modulation by steroids. Behav Genet 1996; 26:497-504.

67.- Gutiérrez-García AG, Contreras CM. El comportamiento sumiso: una estrategia conductual defensiva en los animales y en el humano. Psicología de la Salud 2000; 10:201-13.
68.- Liebenauer LL, Slotnick BM. Social organization and aggression in a group of olfactory bulbectomized male mice. Physiol Behav 1996; 60:403-9.

69.- Guo J, Zhou A, Moss RL. Urine and urine-derived compounds induce c-fos mRNA expression in accesory olfactory bulb. Neuroreport 1997; 8:1679-83.

70.- Tollman J, King JA. The effects of testosterone propionate on aggression in male and female C57BL/10 mice. Anim Behav 1956; 4:147-9.

71.- Barkley MS, Goldman BD. The effects of castration and silastic implants of testosterone on intermale aggression in the mouse. Horm Behav 1977; 9:32-48.

72.- Lombardi JF, Vandenbergh JG. Pheromonally induce sexual maturation in females: Regulation by the social environment of the male. Science 1977; 196:545-6.

73.- Drickamer LC. Effect of period of grouping of donors and duration of stimulus exposure on delay of puberty in female mice by a urinary chemosignals from grouped females. J Reprod Fertil 1983; 69:723-7.

74.- Sandnabba NK. Differences in the capacity of male odours to affect investigatory behavior and different urinary marking patterns in two strains of mice, selectively bred for high and low agressiveness. Behav Process 1985; 11:257-67.

75.- Mosier HD, Grossman HJ, Dingman HF. Physical growth in mental defectives. A study in an institutionalized population. Pediatrics 1965; 36 (Suppl 3):465-519.

76.- Schwanzel-Fukuda M, Bick D, Paff DW. Luteinizing hormone-releasing hormone (LHRH)-expressing cells do not migrate normally in an inherited hypogonadal (Kellmann) syndrome. Brain Res Mol Brain Res 1989; 6:311-26.

77.- Bachmann GA, Kemmann E. Prevalence of oligomenorrhea and amenorrhea in a college population. Am J Obstet Gynecol 1982; 144:98-102.

78.- Petterson F, Fries H, Nillius JJ. Epidemiology of secondary amennorrhea. I. Incidence and prevalence rates. Am J Obstet Gynecol 1973; 117:80-6.

79.- Wasserman EA, Jensen DD. Olfactory stimuli and the "pseudo-extinction" effect. Science 1969; 166:1307-9.

80.- Morrison RR, Kudvigson HW. Discrimination by rats

Vol. 13/No. 3/Julio-Septiembre, 2002 


\section{AG Gutiérrez-García, CM Contreras.}

of conspecific odors of reward and nonreward. Science 1970; 167:904-5.

81.- Collerain Y, Ludvigson W. Hundle-jump responding in the rat as a function of conespecific odor of reward and noreward. Anim Learn Behav 1977; 5:177-83.

82.- Nyby J, Whitney G. Experience affects behavioral responses to sex odors. En Müller-Schwarze D, Silverstein RM, editores. Chemical signals. New York: Plenum Press; 1980. p. 173-192.

83.- Todrank J, Heth G, Johnston RE. Social interaction is necessary for discrimination between and memory for odours of close relatives in Golden Hamsters. Ehology 1999; 105:771-82.

84.- Goldstein NI, Cagen RH. The major histocompatibility complex and olfactory receptors. En Cagen RH, Kare MR, editores. Biochemistry of Taste and Olfactorion. New York: Academic Press; 1981. p. 93-107.

85.- Yamazaki K, Beauchamp GK, Curran M, Bard J, Boyse A. Parent-progeny recognition as a function of $\mathrm{MHC}$ odortype identy. Proc Natl Acad Sci USA 2000; 97:105002 .

86.- Hayashi S, Kimura T. Degree of kinship as a factor regulationg preferences among conespecifics in mice. Anim Behav 1983; 31:81-5.

87.- Penn D, Potts W. How do major histocompatibility complex genes influence odor and mating preferences? Adv Immunol 1998; 69:411-36.

88.- Brown RJ. Mammalian social odors: A critical review. En Rosenblatt R, Hinde L, Berr 1, Busnel M, editores. Advances in the study of behavior. New York: Academic Press; 1979. Vol. 10:103-160.

89.- Brown RE, Bruce R, Singh PB. The MHC and individual odours in rats. En MacDonald DW, MüllerSchwarze D, Natynczuk SE, editores. Chemical signals in vertebrates. Oxford: Oxford University Press; 1990. Vol. 5:228-243.

90.- Valenta JG, Rigby MK. Discrimination of the odor of stressed rats. Science 1968; 161:599-601.

91.- Williams JL, Groux ML. Exposure to various stressors alters preferences for natural odors in rats (Rattus norvegicus). J Comp Psychol 1993; 107:39-47.
92.- Fanselow MS. Odors released by stressed rats produce opioid analgesia in unstressed rats. Behav Neurosci 1985; 99:589-92.

93.- Moynihan JA, Karp JD, Cohen N, Ader R. Immune deviation following stress odor exposure: role of endogenous opioids. J Neuuroimmunol 2000; 102:145-53.

94.- Moynihan JA, Karp JD, Cohen N, Cocke R. Alterations in interleukin-4 and antibody production following pheromone exposure: role of glucocorticoids. J Neuroimmunol 1994; 54:51-8.

95.- Cocke R, Thiessen D. Alarm chemosignals suppress the immune system. En MacDonald DW, Müller-Schwarze D, Natynczuk SE, editores. Chemical signals in vertebrates. Oxford: Oxford University Press; 1990. Vol. 5:125-131.

96.- Cocke R, Moynihan JA, Cohen N, Grota LJ, Ader R. Exposure to conspecific alarm chemosignals alters immune responses in BALB/c mice. Brain Behav Immun 1993; 7:36-46.

97.- Ressler RH, Cialdini RB, Ghoca ML, Kleist SM. Alarm Pheromone in the earthworm Lombricus terrestris. Science 1968; 161:597-9.

98.- MaCkay-Sim A. Discrimination of odors from stressed rats by non-stressed rats. Physiol Behav 1980; 24:699-704.

99.- MaCkay-Sim A. Rats`s responses to blood and body odors of stressed and non-stressed conspecifics. Physiol Behav 1981; 27:503-10.

100.- Abel EL, Hannigan JH. Effects of chronic forced swimming and exposure to alarm substance: physiological and behavioral consequences. Physiol Behav 1992; 52:78185 .

101.- Porsolt RD, Pichon ML, Jalfre M. Depression: a new model sensitive to the antidepressant treatment. Nature 1977; 266:730-2.

102.- Cervo L, Samanin R. Evidence that dopamine mechanisms in the nucleus acumbens are selectively involved in the effect of desipramine in the forced swimming test. Neuropharmacology 1987; 26:1469-72.

103.- Danysz W, Plaznik A, Kostowski W, Malatynska E, Járbe TU, Hiltunen AJ, et al. Comparison of desipramine, amitriptyline, zimeldine and alaproclate in six animal models used to investigate antidepressant drugs. Pharmacol Toxicol 1988; 62:42-50.

\section{Revista Biomédica}


104.- Borsini F, Lecci A, Sessarego A, Frassine R, Meli A. Discovery of antidepressant activity by forced swimming test may depend on pre-exposure of rats to a stressful situation. Psychopharmacology 1989; 97:183-8.

105.- Abel EL, Bilitzke PJ. A possible alarm substance in the forced swimming test. Physiol Behav 1990; 48:233-9.

106.- Hornbuckle PA, Beall T. Escape reactions to the blood of selected mammals by rat. Physiol Behav 1974; 12:5736.

107.- Uziel A. Fisiología de la Olfación. I. Los órganos de los sentidos. En Guerrier Y, Uziel A, editores. Fisiología neurosensorial en otorrinolaringología. Barcelona: Masson; 1985. p. 11 .

108.- Ayesh R, Mitchell SC, Zhang A, Smith RL. The fish odour syndrome: biochemical, familial, and clinical aspects. Brit Med J 1993; 307:655-7.

109.- Malasi TH, El-Hilu SR, Mirza IA, E-Islam MF. Olfatory Delusional Syndrome with various aetiologies. Brit J Psychiat 1990; 156:256-60. 